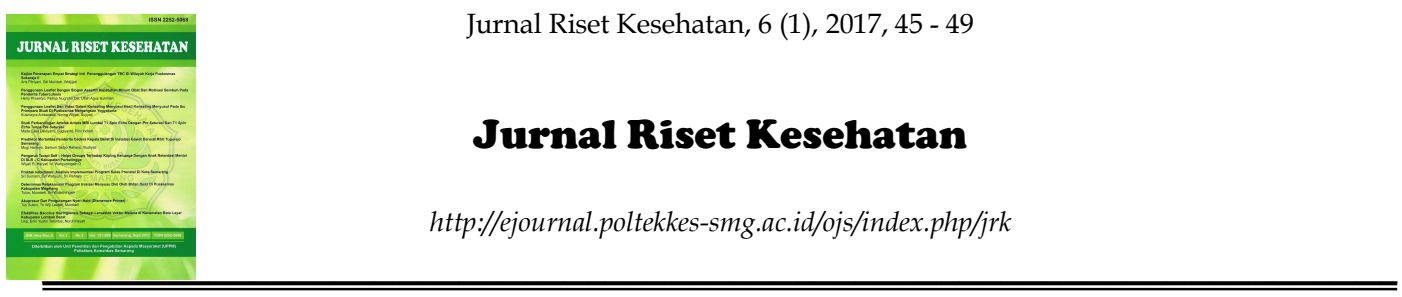

\title{
KEAKURATAN PENENTUAN KODE UNDERLYING CAUSE OF DEATH BERDASARKAN MEDICAL MORTALITY DATA SYSTEM DI RSUD KOTA SALATIGA TAHUN 2016
}

\author{
Linda Widyaningrum*) ; Tyas Kuntari \\ Apikes Citra Medika Surakarta \\ Jalan KH Samanhudi No 93 Sondakan Laweyan; Surakata
}

\begin{abstract}
Abstrak
Underlying Cause of Death merupakan sebab-sebab kematian sebagai semua penyakit, keadaan sakit atau cedera yang menyebabkan atau berperan terhadap terjadinya kematian kalau tidak diderita pasien maka tidak akan meninggal. Tujuan penelitian untuk mengetahui keakuratan Underlying Cause Of Death berdasarkan medical mortality data system (MMDS) di RSUD Kota Salatiga tahun 2016. Penelitian ini menggunakan jenis penelitian non eksperimen, pengambilan data dengan metode observasi dan wawancara dengan pendekatan retrospektif. Populasi penelitian adalah 658 dokumen rekam medis pasien meninggal pada tahun 2016. Jumlah sampel sebanyak 87 dokumen yang diambil dengan teknik random sampling. Instrumen penelitian berupa pedoman wawancara, pedoman observasi, tabel MMDS, ICD-10, dan check list. Persentase keakuratan kode underlying cause of death di RSUD Kota Salatiga tahun 2016 menunjukkan keakuratan kode sebesar 27.59\% akurat dan 72.41\% tidak akurat. Ketidakakuratan dibagi menjadi 3 yakni: (1) Sertifikat tidak diisi dan dikode sebesar $47.62 \%$, (2) Salah penentuan UCoD berdasarkan prinsip umum sebesar $47.62 \%$, (3) Salah penentuan UCoD berdasarkan rule 1 sebesar $4.76 \%$. Sebaiknya mengkode semua diagnosis yang ada disertifikat kematian dan menggunakan aturan mortalitas baik Prinsip Umum, Rule 1, 2 maupun 3 serta merujuk ke tabel MMDS supaya memberikan kode yang akurat.
\end{abstract}

Kata Kunci : Underlying Cause of Death ; Sertifikat kematian ; Tabel MMDS

\begin{abstract}
[CODE DECODING ACCURACY OF UNDERLYING CAUSE OF DEATH BASED ON MEDICAL MORTALITY DATA SYSTEM IN RSUD SALATIGA 2016] Underlying Cause of Death is the cause of death as all illnesses, sickness or injury that cause or contribute to the occurrence of death if not suffered by the patient then will not die. The purpose of this research is to know the accuracy of Underlying Cause Of Death based on medical mortality data sheet at RSUD Kota Salatiga 2016. This research is non experimental research type, data collection with observation method and interview with retrospective approach. The population of the study is 658 document records of patients died in 2016. The number of samples are 87 documents taken by random sampling technique. Instrument of research are the form of interview guide, observation guidance. MMDS table, ICD-10, and check list. The accuracy of underlying cause of death is $27.59 \%$ accurate and $72.41 \%$ is not accurate. Inaccuracy is divided into 3 namely: (1) Certificate not filled and coded equal to $47.62 \%$, (2) One determination of $\mathrm{UCoD}$ based on general principle equal to $47.62 \%$, (3) One determination of UCoD based on rule 1 equal to $4.76 \%$. It is a good idea to code all diagnoses that are certified by death and use the rules of mortality both General Principles, Rule 1, 2 and 3 and refer to MMDS cords to provide accurate code.
\end{abstract}

Keywords: Underlying Cause of Death ; Death certificate ; MMDS Table

\section{Pendahuluan}

Underlying Cause of Death merupakan sebab-sebab kematian sebagai semua penyakit, keadaan sakit atau cedera yang menyebabkan

*) Linda Widyaningrum

E-mail: lindanoumy@gmail.com atau berperan terhadap terjadinya kematian kalau tidak diderita pasien maka tidak akan meninggal (Hatta, 2013). Penentuan Underlying Cause of Death WHO menyusun sertifikat kematian yang merupakan sumber utama data mortalitas yang berasal dari dokumen rekam 
medis pasien dimana rekam medis merupakan suatu data informasi berkaitan dengan tindakan pengobatan diterima pasien selama dirawat (Rustiyanto, 2012). Dokter memiliki tanggung jawab mengisi sertifikat kematian dengan menentukan kondisi sakit yang langsung menyebabkan kematian secara urut menurut urutan kejadian penyakit pasien. Dalam penentuan penyebab dasar kematian dapat digunakan tabel MMDS (Medical Mortality Data Sheet). MMDS Decision Table dipakai yang digunakan untuk menetapkan UCoD (Underlying Cause of Death) yang benar dan penentuan kode penyebab multipel yang tepat. Decision table ini merupakan sekumpulan yang berisi panduan dan arah dalam penerapan rule seleksi dan modifikasi yang dipublikasikan dalam ICD-10 volume 2 (Sarimawar \& Suhardi, 2008). Penyebab kematian dilaporkan memiliki tujuan untuk menghitung angka harapan hidup, angka kematian berdasarkan penyebab dan umur. Selain itu data penyebab dasar kematian dapat digunakan sebagai bahan pertimbangan untuk mengambil keputusan terkait dengan upaya pencegahan dari penyakit untuk meningkatkan status kesehatan masyarakat menjadi lebih baik.

Penetapan UCoD RSUD Salatiga petugas coding hanya mengkode sebab langsung yang tertulis pada lembar kematian pasien yang ditulis oleh dokter. Hal ini menyebabkan masih ditemukan adanya ketidaktepatan dalam penentuan kode penyebab dasar kematian, yang akan berpengaruh terhadap laporan mortalitas yang berkenaan dengan penyakit.

\section{Metode}

Penelitian ini adalah non-eksperimental dimana penelitian yang tidak melakukan upaya upaya tertentu kepada masyarakat maupun objek lainya (Notoatmodjo, 2012). Penelitian ini dimaksudkan untuk meninjau ketidakakuratan Underlying Cause Of Death berdasarkan Medical Mortality Data Sheet (MMDS) di RSUD Kota Salatiga tahun 2016.

Jenis penelitian yang digunakan dalam penelitian ini adalah deskriptif. Hasil dari keakuratan Underlying Cause Of Death dalam penelitian ini akan digambarkan dalam bentuk deskriptif yaitu menggambarkan tentang analisis faktor yang mempengaruhi ketidakakuratan Underlying Cause Of Death di RSUD Kota Salatiga pada tahun 2016.
Metode Pengambilan Data berupa observasi dan wawancara. Observasi dapat dilakukan melalui mencium, melihat, mendengar, dan meraba objek yang akan diteliti. Pada penelitian ini peneliti melakukan pengamatan dan pencatatan terhadap keakuratan Underlying Cause Of Death dengan menggunakan MMDS di RSUD Kota Salatiga tahun 2016. Kegiatan wawancara dilakukan kepada 5 orang petugas yakni 1 kepala rekam medis, 2 orang dokter dan 2 orang coder di RSUD Kota Salatiga.

\section{Hasil dan Pembahasan}

Keakuratan kode penyebab dasar kematian menurut Medical Mortality Data Sheet di RSUD Kota Salatiga tahun 2016 dapat dilihat pada tabel berikut:

Tabel 1. Keakuratan kode penyebab dasar kematian menurut MMDS di RSUD Kota Salatiga tahun 2016

\begin{tabular}{cccc}
\hline No & Akurasi & $\begin{array}{c}\text { Jumlah } \\
\text { Kematian Berdasarkan MMDS }\end{array}$ \\
\hline 1 & Akurat & 24 \\
\hline 2 & Tidak Akurat & 63 \\
\hline
\end{tabular}

Berdasarkan tabel diatas dapat disimpulkan bahwa kode penyebab dasar kematian menurut Medical Mortality Data Sheet yang akurat sebesar 24 dokumen sedangkan kode yang tidak akurat sebesar 63 dokumen. Perbandingan jumlah keakuratan kode dapat dilihat pada diagram berikut:

\section{Keakuratan Underlying Cause Of Death Berdasarkan MMDS}

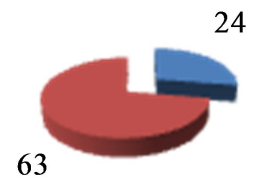

- Akurat

- Tidak Akurat

Gambar 1. Keakuratan Kode Penyebab Dasar Kematian Menurut MMDS di RSUD Kota Salatiga tahun 2016.

Presentase ketepatan hasil kode diagnosis penyebab dasar kematian dengan menggunakan 
Medical Mortality Data Sheet di RSUD Kota Salatiga Tahun 2016 ditunjukkan pada tabel 2.

Tabel 2. Prosentase ketepatan hasil kode diagnosis penyebab dasar kematian dengan menggunakan MMDS di RSUD Kota Salatiga tahun 2016

\begin{tabular}{ccc}
\hline No & Akurasi & Jumlah Dokumen \\
\hline 1 & Akurat & 24 \\
\hline 2 & Tidak Akurat & 63 \\
\hline
\end{tabular}

Berdasarkan Tabel 2 menunjukkan bahwa kode Underlying Cause of Death pada sertifikat kematian pasien meninggal yang akurat sebesar $27.59 \%$ (24 dokumen) lebih kecil dari kode yang tidak akurat sebesar $72.41 \%$ (63 dokumen). Perbandingan prosentase keakuratan kode dapat dilihat pada diagram berikut:

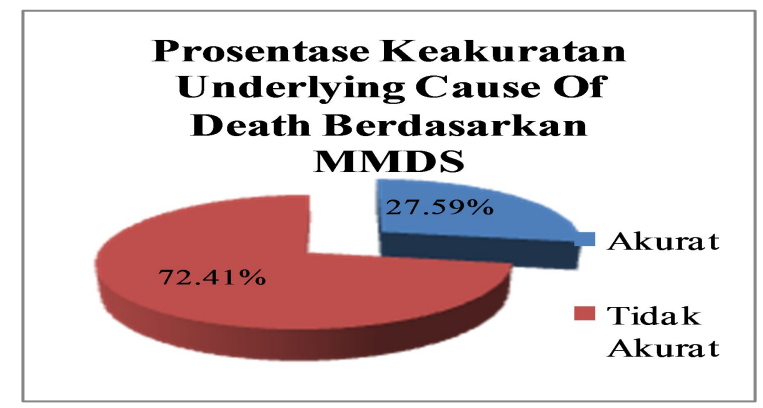

Gambar 2. Prosentase Keakuratan Underlying Cause of Death berdasarkan MMDSdiRSUD Kota Salatiga tahun 2016.

Ketidakakuratan Underlying Cause of Death dapat diklasifikasikan sebagai berikut:

Tabel 3 Klasifikasi ketidakakuratan Underlying Cause of Death berdasarkan MMDS

\begin{tabular}{lc}
\hline \multicolumn{1}{c}{ Kategori } & Jumlah \\
\hline $\begin{array}{l}\text { Sertifikat tidak diisi dan } \\
\text { dikode }\end{array}$ & 30 \\
\hline $\begin{array}{l}\text { Salah dalam menentukan } \\
\text { UCoD berdasarkan pinsip } \\
\text { umum }\end{array}$ & 30 \\
\hline $\begin{array}{l}\text { Salah dalam menentukan } \\
\text { UCoD berdasarrkan rule 1 }\end{array}$ & 3 \\
\hline
\end{tabular}

Berdasarkan tabel 3 menunjukkan bahwa ketidakakuratan kode Underlying Cause of Death berdasarkan MMDS di RSUD Kota Salatiga tahun 2016 yang dikarenakan sertifikat kematian tidak diisi dan dikode sebesar 30 dokumen, kesalahan dalam menentukan UCoD berdasarkan prinsip umum sebesar 30 dokumen dan kesalahan dalam menentukan UCoD berdasarkan rule 1 sebesar 3 dokumen. Perbandingan klasifikasi ketidakakuratan tersebut dapat dilihat pada diagram berikut:

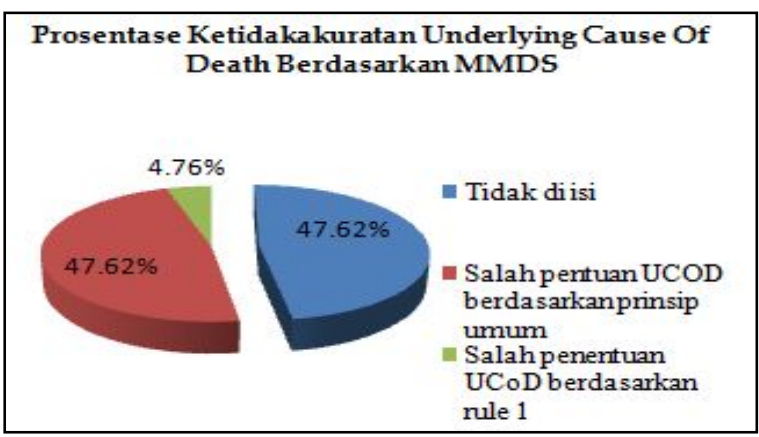

Gambar 3. Prosentase ketidakakuratan Underlying Cause of Death berdasarkan MMDS di RSUD Kota Salatiga tahun 2016

Keakuratan kode diagnosis yang menyebabkan kematian di RSUD Kota Salatiga tahun 2016 Berdasarkan hasil penelitian yang dilakukan di RSUD Kota Salatiga dapat diketahui bahwa keakuratan kode diagnosis yang menyebabkan kematian dari 87 dokumen didapatkan hasil $100 \%$ tidak akurat, atau seluruh dokumen pada sertfikat kematian tidak akurat karena tidak dikode. Petugas coding dalam melakukan pengkodean sebab dasar kematian masih mengacu pada lembar ringkasan masuk dan keluar dan tidak memperhatikan diagnosis yang telah dituliskan dokter pada sertifikat kematian. Apabila diagnosis tidak dikode akan menyebabkan informasi dalam rekam medis tidak akurat untuk mencegah terulangnya kejadian tersebut, diharapkan coder untuk mengisi semua kode dari diagnosis yang ditulis dalam sertifikat kematian pasien sesuai klasifikasi yaitu dengan menggunakan ICD 10 (Depkes RI, 2006). RSUD Kota Salatiga sudah terdapat SPO tentang pengkodean suatu penyakit. Akan tetapi belum ada kebijakan yang mengatur tentang pengkodean diagnosis sebab daasar kematian pada sertifikat kematian. Hal tersebut dapat diatasi dengan adanya kebijakan yang mengatur tentang pelaksanaan pengkodean suatu diagnosis pada sertifikat kematian.

Keakuratan dan ketidakakuratan kode Underlying Cause of Death Berdasarkan hasil penelitian yang dilakukan di RSUD Kota Salatiga dapat diketahui bahwa dokumen rekam medis yang diteliti sebanyak 87 dokumen 
didapatkan hasil kode akurat sebesar 27.59\% (24 dokumen) lebih kecil dari kodetidak akurat sebesar $72.41 \% \quad$ (63 dokumen). Hasil ketidakakuratan tinggi dikarenakan dalam menentukan kode Underlying Cause of Death petugas tidak menggunakan aturan mortalitas sesuai WHO (2010) dan tidak selaras dengan hasil penelitian McKenzie tahun 2013.

Selanjutnya penulis melakukan analisis sebagai berikut:

Ketidakakuratan karena sertifikat kematian tidak diisi dan tidak dikode Ketidakakuratan karena sertifikat kematian tidak diisi dan tidak dikode sebanyak $47.62 \% \quad$ (30 dokumen). Contohnya dalam sertifikat kematian tidak diisi oleh dokter dan semua diagnosis yang tertulis dalam sertifikat kematian pasien semuanya tidak ada yang dikode oleh petugas. Terdapat beberapa dokter yang masih belum melakukan pengisian sertifikat kematian serta masih adanya kendala dari dokter dalam menentukan urutan sebab kematian dari pasien, kemudian petugas coding belum melakukan pengkodean terhadap urutan diagnosis pada sertifikat kematian. Hal ini tidak sesuai dengan Depkes RI (2006) bahwa kegiatan dan tindakan serta diagnosis yang ada didalam rekam medis harus diberi kode.

Salah Penentuan UCOD dan Kode ketidakakuratan kode Underlying Cause of Death karena salah penentuan UCOD berdasarkan prinsip umum sebanyak $47.62 \%$ (30 dokumen) dan salah dalam menentukan UCOD berdasrkan rule 1 sebanyak $4.76 \%$ (3 dokumen), sebagai contoh dalam sertifikat kematian pada bagaian satu terdapat diagnosa yang di tulis dokter yaitu Cardiact arrest (I46.9) CKD (N18.9) dan DM (E14.9), rumah sakit menentukan Underlying Cause of Death yaitu Anemia dengan kode D64.9 seharusnya menurut tabel MMDS bukan anemia sebagai Underlying Cause of Death tetapi DM dengan kode E14.9. Kedua salah penentuan UcoD dan kode berdasarkan Rule 1 sebagai contoh sertifikat kematian terdapat Distress respiratory (P22.9) BBLR (P07.1) dan Asphyxia Berat (P21.0) rumah sakit menentukan Underlying Cause of Death yaitu asphyxia berat dengan kode P21.0 seharusnya menurut tabel MMDS bukan asphyxia berat sebagai Underlying Cause of Death tetapi BBLR dengan kode P07.1 dengan menggunakan rule 1 . Rule 1 diterapkan jika terdapat lebih dari satu kondisi yang dilaporkan pada sertifikat, tetapi prinsip umum tidak dapat diterapkan, maka pilihlah kondisi yang diisikan tersendiri sebagai penyebab dasar apabila kondisi itu merupakan penyebab mula-mula dari urutan yang berakhir dengan kondisi yang diisikan pertama pada sertifikat. Solusi untuk mencegah terulangnya kejadian tersebut yaitu coder dianjurkan menggunakan aturan mortalitas baik Prinsip Umum, Rule 1, 2, maupun 3 sesuai yang ditetapkan oleh WHO (2010) ataupun Depkes RI (2006).

\section{Simpulan dan Saran}

Keakuratan kode Underlying Cause of Death pada sertifikat kematian pasien berdasarkan ICD-10 dan tabel MMDS di RSUD Kota Salatiga adalah sebesar $27.59 \%$ (24 dokumen) kemudian yang tidak akurat sebesar 71.41\% (63 dokumen). Ketidakakuratan disebabkan karena sertifikat kematian tidak diisi dan dikode yaitu sebanyak 47.62\% (30 dokumen), salah dalam menentukan UCoD berdasarkan prinsip umum rule 1,2 maupun 3 serta pengecekan ulang ke tabel MMDS sehingga dapat menghasilkan kode Underlying Cause of Death yang akurat.

Sebaiknya semua diagnosis yang ada di sertifikat kematian pasien di lakukan pengkodean dengan menggunakan aturan mortalitas baik prinsip umum, rule 1,2 maupun 3 serta pengecekan ulang ke tabel MMDS sehingga dapat menghasilkan kode Underlying Cause of Death yang akurat.

\section{Ucapan Terima Kasih}

Terima kasih disampaikan kepada Direktur Apikes Citra Medika Surakarta dan Politeknik Kesehatan Kemenkes Semarang yang telah memberikan kesempatan untuk menerbitkan jurnal ilmiah ini.

\section{Daftar Pustaka}

Arikunto, S. 2013. Prosedur Penelitian Suatu Pendekatan Praktik. Jakarta:Rineka Cipta.

Departemen Kesehatan Republik Indonesia. 2006. Pengelolaan Rekam Medis Rumah Sakit Di Indonesia Revisi II. Jakarta.

Hatta, G. 2013. Pedoman Manajemen Informasi Kesehatan di Sarana Pelayanan Kesehatan. Edisi Revisi.Jakarta: Universitas Indonesia (UIPress).

McKenzie, Kirsten, Etc.2003. Correlates of undefined cause of injury coded mortality data in Australia. Health information management journal vol 38 no 12009 issn 1833-3583. Australia: Queensland Unersity 
of Technology. Diakses pada tanggal 10 April 2017 pukul 09.30.

Notoatmodjo, S. 2012. Metodologi Penelitian Kesehatan. EdisiRevisi Pertama. Jakarta: PT Rineka Cipta.

Rustiyanto. 2012. Etika Profesi Perekam Medis $\mathcal{E}$ Informasi Kesehatan.Yogyakarta : Graha Ilmu.

Sarimawar ,Suhardi. 2008. Buku Pedoman Penentuan Kode Penyebab Kematian Menurut ICD10.Jakarta: Badan Penelitian dan Pengembangan Kesehatan, Kementrian Kesehatan RI 2016

Saryono dan Anggraeni. 2013. Metodologi Penelitian Kualitatif Kuantitatif Dalam Bidang Kesehatan. Yogyakarta: Nuha Medika

Sugiyono. 2014. Metode Penelitian Kuantitatif Kualitatif dan RED. Bandung: Alfabeta.

World Health Organization, 2010.International Statistical Clasification Of Diseases And Related Health Problems (ICD-10,Volume 2), Geneva. 